\title{
Pancreas Retrieval for Whole Organ and Islet Cell Transplantation
}

\author{
Wayne J. Hawthorne, Ahmer Hameed and \\ Henry Pleass
}

Additional information is available at the end of the chapter

http://dx.doi.org/10.5772/intechopen.75151

\begin{abstract}
For more than five decades, we have been refining advances in pancreas whole organ and islet cell transplantation as clinical therapies to treat the ever-increasing number of patients suffering from type-1-diabetes. Research and clinical practice have contributed to making both whole organ and cellular transplantation viable therapeutic options for a broader range of patients. Furthermore, both forms of clinical transplantation results have progressively improved, due to the ongoing refinement of organ donation and its various technical processes, combined with the evolution of immunosuppression and patient care now offering excellent long-term treatment for both type-1-diabetes and concomitant renal failure. This chapter provides an overview on how this has been undertaken and achieved over decades to ultimately provide outstanding outcomes on par with other organ transplantation results. Briefly, we cover the history of pancreas retrieval procedures, the importance of donor selection, the intricate processes of the organ donor operation, preservation of the pancreas, and the ideal ways to best improve outcomes for transplantation. Improving and providing the optimal donor and preservation conditions underpinning the success of subsequent whole pancreas or islet transplantation as a safe, effective, and feasible therapeutic option for an increasing number of patients suffering from type-1-diabetes.
\end{abstract}

Keywords: diabetes, insulin, islet, islet cell, islet cell allotransplantation, islet cell transplantation, islet cell isolation, organ perfusion, organ retrieval, renal failure, type 1 diabetes, whole organ transplantation 


\section{Introduction}

Since Kelly and colleagues performed the first whole pancreas transplant in 1966, significant advancements in pancreas transplantation have been made. [1] There was a gap following the first series of whole pancreas transplants due to poor graft outcomes with significant impact from poor organ preservation of the pancreas playing a major role. It took almost 20 years for the development of newer surgical techniques including use of newly developed perfusion solutions, segmental grafts, advances in ductal drainage including bladder drainage, and effective immunosuppression regimens such that whole organ transplantation burgeoned, with great advances made by Sutherland and colleagues at the University of Minnesota [2]. However, it was not until much later following many years of experimental research that pancreata for islet cell isolation and transplantation became a reality. Over the past two decades in particular a great deal of effort has underpinned making islet cell transplantation a viable therapy for a broader range of patients with type 1 diabetes (T1D). Clinical results have progressively improved, now demonstrating outcomes on par with other organ transplants, specifically in terms of insulin independence, and graft and patient survival [3]. We are now at the point where islet cell transplantation, in the form of allotransplantation, like its forebear whole organ transplantation, has become widely accepted as a clinical therapy for patients affected by T1D.

Now more than five decades on and with many organ donor operations having been performed since the advent of organ donor procedures as we know them, we have refined and perfected the organ donor process since the first organ retrieval of a brain dead donor in 1963 [4] and the subsequent adoption of the "Acceptance of Brain Death for Organ Donation" issued by the Ad Hoc Committee of the Harvard Medical School [5]. We have seen an increasing emergence of specialized organ retrieval teams with focus on the overwhelming need to improve organ donor rates for the ever increasing recipient patient population [6]. Always a dedicated surgical pursuit, research into organ donation and the surgical retrieval process for the pancreas and most other organs has often been overlooked in favor of recipientrelated research into the prevention of rejection, and improving immunosuppression and tissue matching. This is particularly problematic when it comes to whole pancreas and islet transplantation as the pancreas is a less retrieval tolerant organ than other solid organs, and requires extra attention both during and after retrieval to ensure that the organ's valuable islets, which are especially susceptible to hypoxia and the ischemic insult, are effectively preserved $[7,8]$.

In this chapter we provide a general overview of Pancreas Retrieval for both Whole Organ and Islet Cell Transplantation, but it should be noted that there are clear overlaps in this process for both whole organ and cellular transplantation. As such the way the processes are performed can be utilized for retrieval for either type of subsequent transplant. Overall, we have seen significant improvements to pancreas transplantation results, in particular in the islet cell arena, due to the significant research undertaken to improve graft outcomes by improving donor selection and organ procurement and preservation [9]. On the recipient side we have also further improved outcomes with changes to the transplant and to the 
pharmacological treatment of recipients such as newer focused monoclonal immunosuppressive strategies that better control graft rejection [9].

This chapter focuses on the optimal process for deceased donor pancreas retrieval and its role in maximizing graft function and survival. However, with a great number of processes to outline, only the major ones will be covered in this chapter. In particular, we will emphasize major improvements in donor selection, surgical retrieval techniques, pancreas retrieval in the context of multi-organ donors, back-table preparation of the pancreas, perfusion fluid types, and future perspectives including the utilization of technologies such as machine perfusion and persufflation. These factors will be discussed in the context of improved outcomes to the engraftment, function and survival of the transplants. It is also acknowledged that there remains the ongoing need for further improvements to both whole organ and islet cell transplantation, however both techniques clearly offer safe and achievable therapeutic options for the ever-expanding number of patients suffering from T1D [10].

\section{Historical timeline}

The original retrieval processes of the modern era were initially developed for and used in kidney only retrieval surgery. As per Figure 1 the procedure first introduced in 1963 utilized cold lactated Ringer's or low-molecular-weight dextran solutions infused directly into the renal artery of the retrieved kidneys, performed only after their removal from the donor [11]. These were the beginnings of modern donor retrieval but they were less than ideal techniques due to the time taken to perfuse the organs, and therefore a number of more active and by far more effective methods of perfusion and cooling of organs were subsequently developed in order to minimize ischemic insult and subsequent damage to organs. These techniques were based upon the concepts from cardiothoracic surgery, involving active patient cooling during procedures to prevent ischemic damage $[12,13]$. The transplant fraternity quickly adopted these intravascular perfusion-related cooling techniques, which were standardly utilized as a first step in the preservation of all whole-organ grafts. The currently accepted modern cadaveric donor procedure is performed using some basal form of the ex situ techniques developed and performed in the mid to late 60's by Starzl and colleagues [14] for not only kidneys but also incorporating the pancreas and liver. Further refinements saw the perfusion and addition of heparin to the perfusate solutions and also the donor. Ensuring removal of blood by ex situ perfusion as described by Belzer et al. [15] resulted in improved but only satisfactory kidney preservation of several days. However, this technique was eventually abandoned in most kidney transplant centers when it was learned that the quality of 2-day preservation was no better than with the simpler "iced slush" methods [16].

The underpinning method of iced slush for shipping was based around experimental work on kidneys [17]. This research and practice focused on perfusion fluids of differing intracellular and extracellular fluids consisting of electrolytes with varying osmotic and oncotic effects that were infused into the allograft before placing it in a cold storage container. Collins 


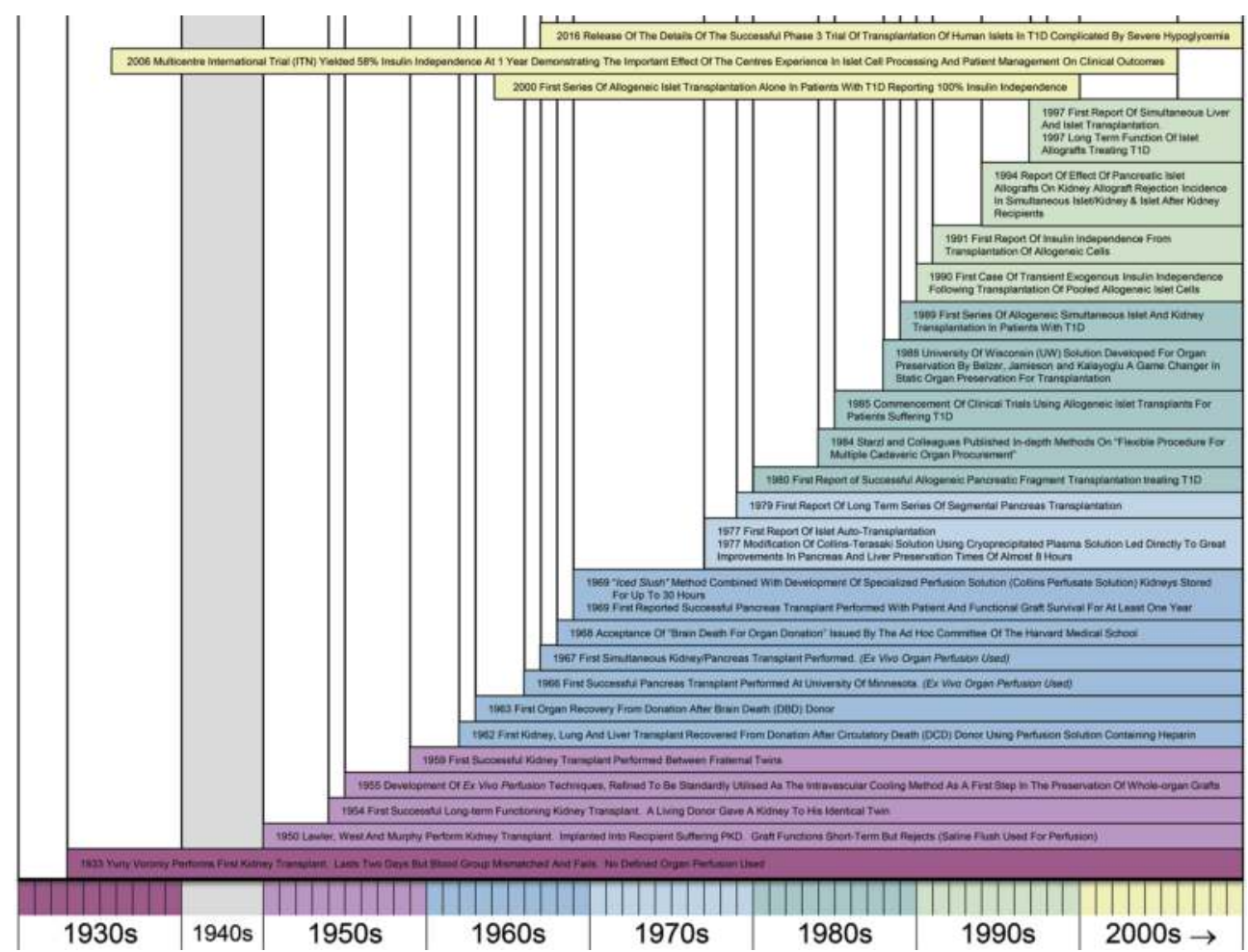

Figure 1. A time line in the significant development of transplantation over the years with focus on the techniques used for whole pancreas and islet cell transplantation.

and colleagues developed a relatively simple technique (infusion of mannitol, phenoxybenzamine, and their Collins perfusate) providing good preservation in kidneys stored for up to 30 hours [17]. Other perfusates, such as Ringer's lactate and 10\% invert-sugar solutions, gave inferior results. The new perfusate solution and technique extended the time of simple ice storage from 12 hours to 30 hours. Continuous hypothermic perfusion saw further additions by Ackerman and Snell [18] and Merkel, Jonasson, and Bergan [19] who following many organ donor studies developed the widely accepted and much more simplified core cooling. These utilized cold perfusion solutions with the infusion of the fluids being performed directly to the vascular bed of all the organs via the distal aorta and demonstrated significant improvement for the pancreas but they were still less than ideal for this most sensitive organ. However, the development of these techniques used throughout the 70's meant that organs could generally be removed without causing issues when retrieving multiple organs, which included the liver and sometimes pancreas. Kidney preservation became more feasible along with the other abdominal organs seeing times of 1 to 2 days, long enough to allow tissue matching and sharing of organs between hospital units even interstate or in Europe between countries. However, these were purely focused still on the kidneys rather than the other abdominal organs and as such a number of groups undertook experiments focusing on other organs including the pancreas and liver; landmark papers included those by Benichou 
et al. [20], using the Collins-Terasaki solution, and de Gruyl et al. [21] using cryoprecipitated plasma perfusion preservation of duct-ligated pancreatic allografts, along with Wall et al. [22] using similar plasma-like solution. This led directly to great improvements in pancreas and liver preservation and allowed organ sharing amongst transplant centers, although the preservation period was still limited to less than 8 hours.

The development of University of Wisconsin (UW) solution for organ preservation by Belzer, Jamieson, and Kalayoglu in the 1980s was a game changer in static organ preservation for transplantation [23]. This new flushout solution for preservation of the pancreas was tested in the dog model of segmental pancreas autotransplantation. The solution has an osmolality of $320 \mathrm{mOsm} / \mathrm{L}(\mathrm{K}+=120 \mathrm{mM}, \mathrm{Na}+=30 \mathrm{mM})$, and contains lactobionate, and raffinose as impermeants. The role of hydroxyethyl starch (HES), the colloid component of UW solution, was shown to be particularly important for pancreas preservation, in comparison to the liver and kidney [24]. UW perfusate solution preservation almost tripled the time of safe preservation of the various organs, including the pancreas, making national sharing of most organs a viable and practical process [25].

However, despite significant success the preservation or extended preservation of the pancreas still required further refinement, and significant research using animal models of static perfusion were pursued, in particular for use in islet cell transplantation. Along with perfusion fluids a number of standardly used retrieval techniques became more readily adopted [19]. However, until 1981 transplantation of the extra-renal organs was an unusual event such that the focus of perfusion only really focused on kidneys. By the mid-1980s, it became apparent that multiple organs would start to become transplanted in earnest, with liver, pancreas and thoracic organ transplant procedures becoming more widely accepted. A safe and effective method for multi-organ procurement and preservation was required by which the abdominal organs, kidneys, liver, and pancreas, could all be suitably retrieved using the same solution. At this stage Starzl and colleagues published an in-depth method on their "flexible procedure for multiple cadaveric organ procurement" [26], which was adopted by many centers worldwide.

However, even at this point the pancreas was often over-looked with the focus on the kidneys and liver as the principal organs to be retrieved. Starzl's publication stated "If the whole pancreas is transplanted as we recommend, the combination of liver and pancreas removal is incompatible" and it was often the case when surgical teams were procuring the liver and pancreas together that there were issues relating to the suitable separation of their vasculature [27]. At this time, our own surgical team also retrieved the pancreas with the liver, but always removed liver to the back-table before the pancreas and kidneys. The major perceived reason for this was the need for the lifesaving liver to take priority. Furthermore, as the portal vein and the branches of the celiac trunk, drain or supply both organs, preference was given to sacrificing the pancreas' vessels instead of the liver. It was a number of years before this routine surgical practice would change.

Whole organ research utilized canine models as the dog pancreas is more anatomically similar to humans in comparison to the tri-lobed porcine pancreas. These models allowed replication of the clinical situation and further refinement of the retrieval and transplant procedures [28, 29]. From these came the widespread implementation of newer perfusion fluids such as UW solution, and the utilization of vascular extension grafts to the pancreatic vasculature helped resolve the situation of shortened pancreatic inflow and outflow conduits due to preference to 
the liver in combined retrievals [30]. The other major change to the procedure was the adoption of an en bloc liver pancreas retrieval technique, where both organs were rapidly removed in a bloodless field post perfusion, then separated on the back-table. Furthermore, the sharing of organs from a common donor by recipient teams from different units became routine by the early-1990s, in particular due to the use of UW solution, which had clearly been shown to be a real advantage in pancreas retrieval both experimentally and clinically [31].

In the 1990's the focus on research and advances relating to the retrieval process started to shift, with attention once again shifting to the perfusate solutions, which were thought to be especially impactful for islet cell transplantation. A number of groups also investigated additives to the perfusate solutions such as the use of antibodies to reduce inflammation and further improve graft outcomes, although this was met with limited success [32]. In the 2000's it became generally accepted this was achieved via cannulation of the aorta alone, with or without additional access to the portal venous system with variations that have been seen specifically in relation to multiorgan retrieval where some groups chose to perform 'dual' perfusion technique which are all discussed in greater detail later in this chapter [33, 34].

\section{Use of the pancreas for whole organ or cellular transplantation- donor selection}

Underpinning the entire transplantation process, regardless of whether the donor is for whole pancreas or islet cell transplantation, is appropriate donor selection such that the donor organ is of a suitable size and quality to allow for use in either type of therapy. In order to be utilized in clinical transplantation, it is imperative that the donor be appropriately screened to ensure the organ to be retrieved is free from any disease that may subsequently manifest in the donor, including cancer, and infections with viruses, bacteria, fungi, or prions [9]. It is paramount that we avoid the more commonly occurring diseases when screening the donor before accepting the pancreas for organ donor retrieval and subsequent clinical transplantation. Infectious risk factors depend on the history of patient, any underlying disease of the organ donor, and the immunosuppressive treatment administered to the recipient [35]. Transmission of most pathogens is possible, but their frequency varies according to the endemic population from the transplanted organ, the selected immunosuppressive therapy and prophylaxis utilized in the recipient, and also at the donor procedure [36]. Obviously, there are many more variables with regards to organ donor selection criteria, and these will be discussed in more detail in the following sections.

\section{Pancreas retrieval}

\subsection{Surgical techniques}

Pancreas retrieval for both whole organ and cellular transplantation necessitates meticulous surgical technique. In comparison to the liver and kidneys, the pancreas is more commonly damaged at retrieval, which subsequently results in non-utilization of a significant proportion 
of procured pancreata [37]. The organ must be procured without any parenchymal and/or capsular breach, and its arterial inflow and venous outflow vessels must be clearly identified (tagged) and maintained for subsequent back-table reconstruction when used for whole pancreas [38]. The extent of organ and vascular dissection depends upon whether the retrieval is from a brain-dead (DBD) or circulatory death (DCD) donor; a large proportion of pancreas dissection can be undertaken in the warm phase for DBD donors, whilst pursuit of the DCD pathway necessitates wholly cold-phase dissection, which is potentially more difficult as appropriate anatomy is harder to identify.

\subsubsection{Anatomical considerations}

The pancreas is situated in the retroperitoneum, nestled within the curvature of the duodenum. Important relations are both kidneys posteriorly, the spleen laterally and attached to the pancreas via its pedicle contained within the lienorenal ligament, the superior mesenteric vessels, bile duct, and portal vein in the region of the pancreatic head/neck, the inferior vena cava (IVC) deep to the head and portal vein, and the aorta, left suprarenal gland and left renal vein deep to the body. Pancreatic blood supply is primarily derived from the celiac artery in origin via the splenic and superior mesenteric arteries (via the inferior pancreaticoduodenal artery), and also the gastroduodenal artery (via the superior pancreaticoduodenal artery). The celiac trunk gives off the splenic artery, which emerges at the upper pancreatic border and runs along this border in a tortuous fashion until turning towards the splenic hilum within the lienorenal ligament. The superior mesenteric artery (SMA) emerges from the aorta inferior to the celiac trunk, and is directed inferiorly on the posterior aspect of the pancreatic neck, to then lie on the uncinate process and then the 3rd part of the duodenum prior to entering the root of the mesentery. Venous drainage occurs via the splenic vein for a large part of the pancreas, whilst the superior and inferior pancreaticoduodenal veins drain the head into the superior mesenteric vein (SMV) and portal vein confluence. It is the shared vasculature of the pancreas with the liver that often causes retrieval issues as the origin of the splenic artery is from the celiac, and the outflow of the splenic vein is through the portal vein, necessitating delicate surgical dissection and care in separation to ensure shared and usable vasculature for both organs [39].

\subsubsection{DBD retrievals - pancreas-specific considerations}

Pancreas retrieval in the DBD donor is a controlled process that allows significant preliminary organ and vascular pedicle dissection. The Cattell-Braasch maneuver is utilized to expose the aorta and IVC distally, with the proximal extent of dissection limited by the SMA overlying the left renal vein; this maneuver will incorporate mobilization of the small bowel mesentery and pancreatic head/duodenum [40]. Our approach to exposure and dissection of the remaining pancreas [41] is to access the lesser sac by mobilization of the greater curvature of the stomach; the greater omentum is detached at its origin using ultrasonic shears (Harmonic Scalpel) as per Figure 2. The short gastric vessels are also detached using this method at the upper portion of the greater curvature. The splenic flexure of the large bowel can thence be mobilized onto the lower pole of the spleen. Once the spleen is free of its surrounding attachments, it can be lifted and used as a handle to mobilize the tail and body of the pancreas without directly 
handling the pancreas itself. The Harmonic Scalpel is also very useful in the dissection of the superior and inferior pancreatic borders, particularly the relatively vascular splenic flexure of the colon. The posterior surface of the pancreas can be mobilized with standard electrocautery in a relatively bloodless plane. The SMA/SMV pedicle inferior to the pancreas needs to be skeletonized such that it can be divided using a vascular stapler prior to pancreas removal in the cold phase. Superiorly, the bile duct is ligated and transected proximal to the point of ligation; residual bile is flushed out its open proximal end using saline instilled into the gallbladder. We will also free attachments around the gastroduodenal junction and duodenojejunal flexure, which are then identified with circumferential vessel loops for stapled division later in the cold phase. The inferior mesenteric vein is ligated in situ post perfusion as subsequent retraction of the divided vessel may make it difficult to identify on the back-table. Diluted povidoneiodine solution is instilled into the duodenum via a nasogastric tube as a decontamination step, and is subsequently removed through the same route. Some authors report concerns with subsequent duodenal mucosal toxicity related to instillation of povidone-iodine, and
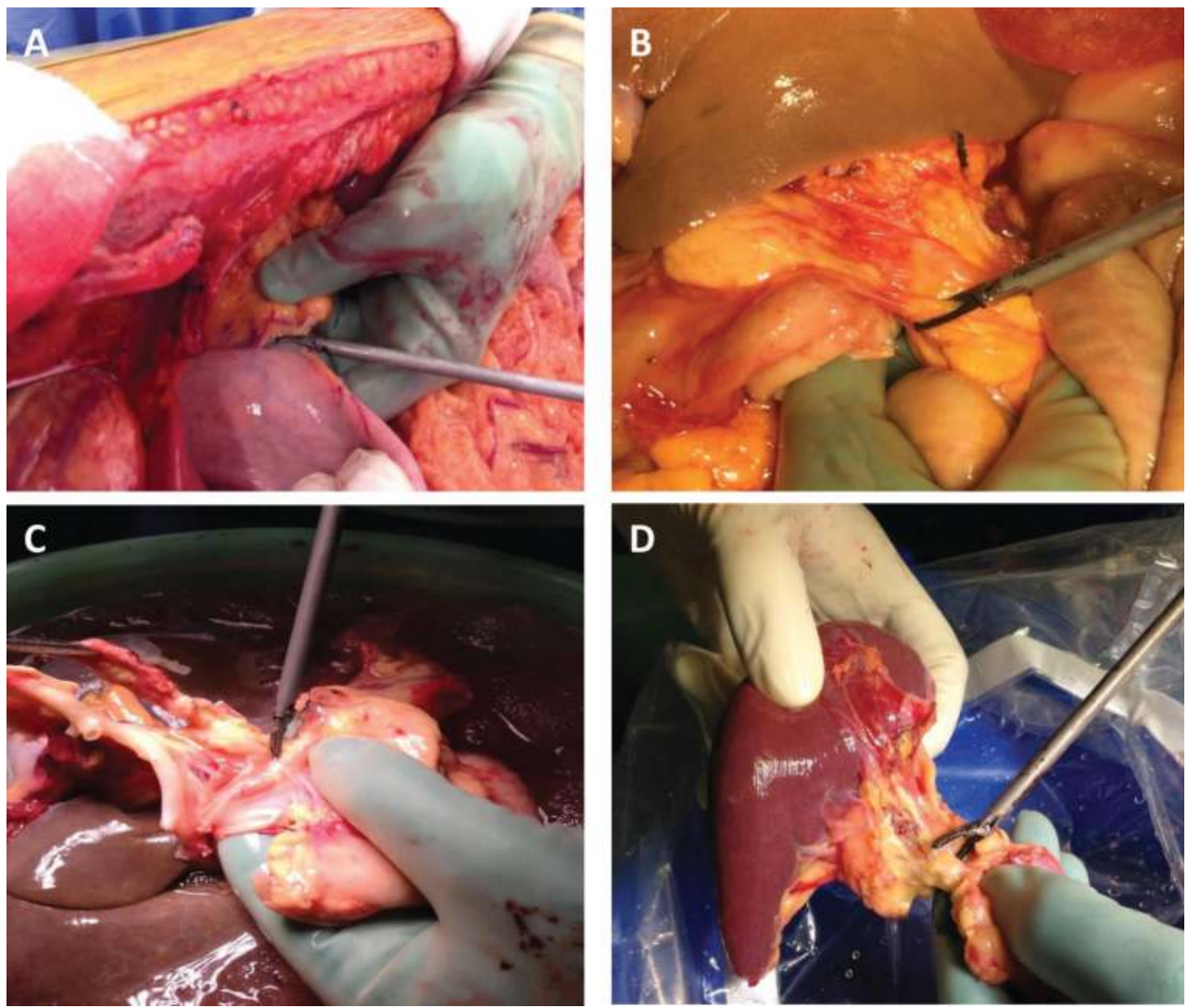

Figure 2. The harmonic scalpels utilization during pancreas procurement. (A) Mobilization of the greater curvature of the stomach, (B) creation of the superior mesenteric pedicle (cold phase), and back-table separation of (C) the liverpancreas block, and (D) the pancreas and spleen. 
suggest additional back-table flushing of the duodenum with an alternate solution [42, 43]. Alternatively, duodenal decontamination can be completed using an antibiotic solution, such as amphotericin [40]. However, the most important factor is to utilize a decontamination procedure to reduce the potential risk of cross infection to the recipient. Our own unit has utilized povidone-iodine solution instilled into the duodenum via a nasogastric tube as a decontamination step in more than 500 SPK transplants at our own center with no duodenal mucosal toxicity identified [44]. In the cold phase the duodenum is then divided above and below the pancreatic head with a linear cutting stapler, after carefully withdrawing the nasogastric tube from the duodenum into the body of the stomach. Any remaining superior mesenteric pedicle dissection is also completed, and a vascular (cutting) stapler is utilized to divide this pedicle. It is of paramount importance that the pancreas is not injured during this step as this will cause serious issues in both whole organ and islet cell transplantation. Furthermore, if the mesenteric pedicle is divided too close to the pancreas, or includes part of the uncinate process, there is a risk that blood supply to the pancreatic head via the inferior pancreaticoduodenal branch of the SMA will be compromised, creating a significant problem for whole organ transplantation $[40,45,46]$. Additionally, for the whole organ transplant an arterial and venous conduit should be retrieved for back-table pancreatic vascular reconstruction. This usually consists of a segment of the external iliac vein for use as a portal vein extension graft if required, and the common iliac artery bifurcation, including a length of the internal and external iliac arteries, to fashion a Y-graft connecting the native SMA and splenic artery. It is essential that the common iliac bifurcation is not damaged during this process [45]. Like a number of other major units our center preferentially retrieves the pancreas en bloc with the liver, with separation of both organs performed on the back-table (see below) [47].

\subsubsection{DCD retrievals}

DCD pancreas retrieval is technically feasible, and can achieve excellent outcomes in selected donors certainly in the whole organ arena (see Outcomes, below). In contrast to DBD procurement, the first step in all DCD retrievals after a rapid laparotomy is cannulation and cold perfusion via the aorta [48, 49]. Venous venting is conducted via the IVC. Alternatively, if local laws allow, an in situ flush can be achieved using femoral cannulae inserted prior to the withdrawal of life support $[49,50]$. Ante-mortem interventions including heparinization have been shown to also provide significant improvements to pancreas retrieval outcomes in the DCD setting [51]. Standard pancreas retrieval can then be undertaken as described for DBD donors, although donor hemostasis is no longer a concern and therefore sharp dissection is commonly utilized. The use of energy devices such as the Harmonic Scalpel at this stage may help minimize recipient bleeding however, as described in the DBD setting.

\subsubsection{Pancreas retrieval and multi-organ donors}

Pancreas retrieval is almost never undertaken in isolation, but rather it is usually procured in the context of a multi-organ retrieval, often in the presence of multiple retrieval teams. Meticulous retrieval technique therefore needs to be maintained and balanced in the presence of these competing factors, especially in the presence of concomitant liver procurement, which is still given preference owing to the critical requirement of liver transplant recipients. 
Pancreas-alone donors are uncommon in this day and age due to developments in procurement and preservation techniques. Some authors raised concerns that combined liver-pancreas retrieval, in contrast to pancreas retrieval alone, resulted in significant "flush" injury to the pancreas owing to a higher volume of perfusion solution and the utilization of dual aortoportal cannulation in the combined donors [52]. However, other studies clearly demonstrated that multi-organ retrieval, including combined liver-pancreas retrieval, was not detrimental to pancreas transplantation outcomes [53-58]. Another factor that previously precluded combined liver-pancreas procurement was aberrant hepatic arterial anatomy, in particular the presence of an aberrant or accessory right hepatic artery originating from the superior mesenteric artery [58]. Abandoning retrieval of the pancreas due to this situation is now rare, as a preserved length of the right hepatic artery originating from the SMA stump can effectively be anastomosed to the GDA as part of a back-table reconstructive procedure [45, 46]. It is only when the right hepatic artery is within the substance of the pancreas that whole pancreas retrieval should be precluded in favor of the liver [59] but the pancreas can still be retrieved for islet cell isolation as the pancreas can still be readily perfused, and on the back table the vessels readily separated, including if necessary taking them from the body of the pancreas [9]. However, if this is undertaken then care should be taken to not damage the parenchyma of the pancreas as this makes the distension of the pancreas with collagenase for digestion more difficult [9]. Over the last 25 years and more than 1000 retrievals the authors have never found any anatomical vascular anomaly to prevent an en bloc liver-pancreas retrieval, although this is cited as a common reason to decline pancreas retrieval worldwide.

\subsubsection{Back-table separation of the liver-pancreas block and further back-table preparation of the pancreas}

The combined liver-pancreas block is taken to the back-table for separation. The aortic segment is divided such that the proximal portion of the SMA remains with the pancreas, whilst the celiac axis remains in continuity with the liver. Superior to the pancreatic head, the portal vein is divided approximately $1 \mathrm{~cm}$ from the pancreas, whilst the splenic artery is divided closer to its emergence from the celiac axis $[45,46]$. The GDA is ligated and divided prior to entering the pancreas; a longer length remains with the liver. The splenic artery and portal vein associated with the pancreas should be marked with a prolene suture to facilitate identification at the transplant center. The spleen is also routinely removed at the donor hospital, in addition to skeletonization of the pancreas prior to transportation. The Harmonic Scalpel is once again a useful tool that facilitates all pancreas-related back-table work if the graft is to be used for whole pancreas transplantation [41]. Limited back-table perfusion of the pancreas with UW solution is employed to ensure no blood is left within the organ or its vessels, whilst minimizing the risk of graft pancreatitis or edema.

In pancreas retrievals for islet cell isolation, the author's use a similar en bloc technique, with careful mobilization of the pancreas prior to aortic cannulation as per Figure 3. However, there is no need for meticulous hemostasis post perfusion and it is not necessary to remove the bulk of the tissues as this can be performed at the islet isolation facility. At the isolation center, the duodenum, spleen, and connective, extracapsular and vascular tissues are removed from the pancreas prior to it being cannulated to allow infusion of the digestive collagenase enzyme for 

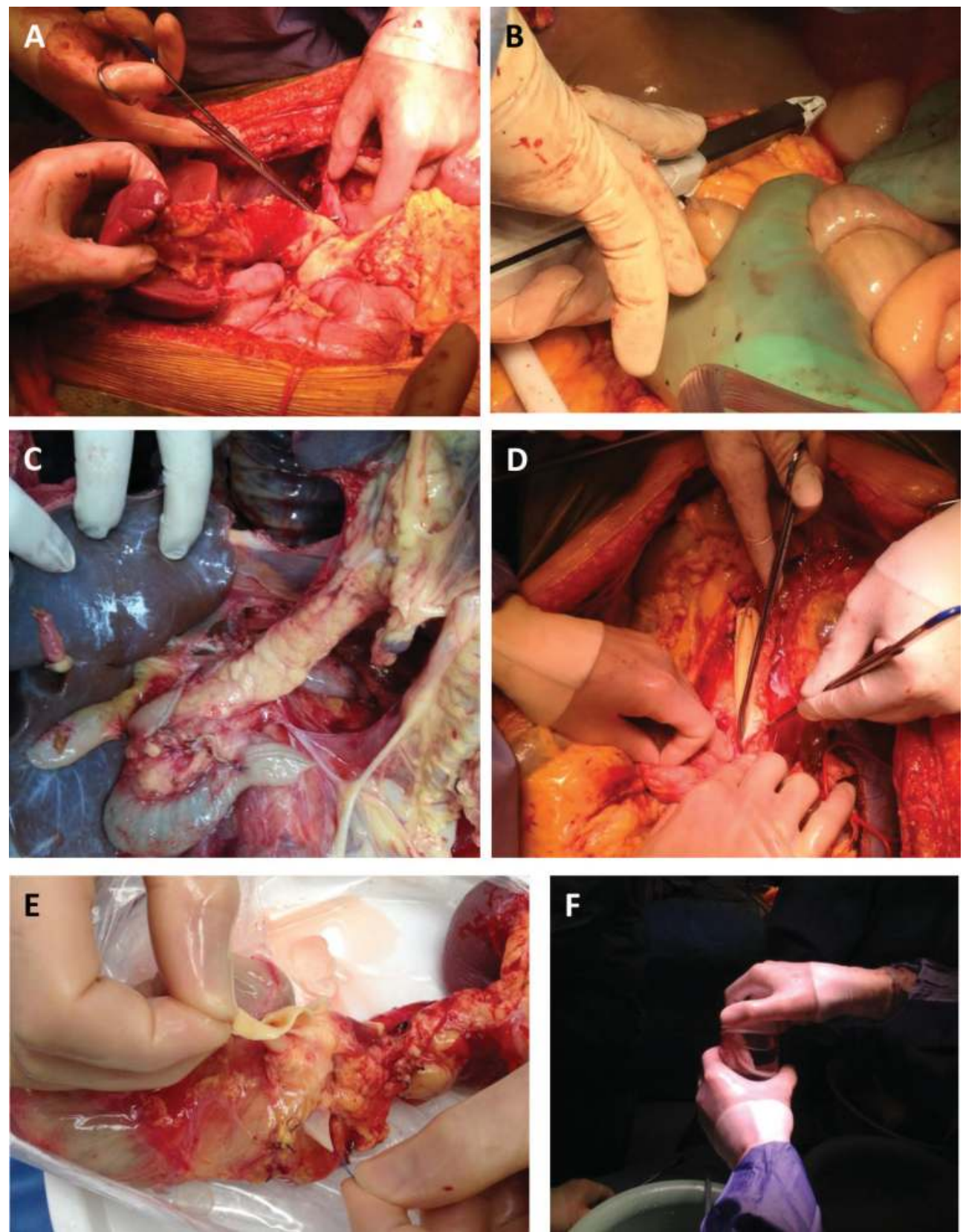

Figure 3. Procurement of the DBD pancreas. (A) Skeletonization of the pancreas, using the spleen as a handle, (B) stapled division of the superior mesenteric pedicle, (C) liver and pancreas ready for en bloc removal, (D) division of the aorta, (E) pancreas appearance after back-table preparation (n.b. Portal vein and superior mesenteric artery), and (F) back-table packing of iliac conduits in preservation solution. 
islet cell isolation [9]. As such there is also no need for preservation of pancreas vasculature, which can be given wholly to the liver when separated on the back-table.

\subsubsection{Pancreatic inspection and graft assessment}

The pancreas must be closely inspected during the retrieval process, and any concerns regarding organ quality and/or integrity should be fully conveyed to the implanting surgeon. Graft assessment should include qualities inherent to the donor pancreas, in addition to any retrieval-related damage, and should be made both in situ and on the back-table as per Figure 3. The pancreas should be assessed for parenchymal damage, capsular breach, and/or hematoma(s). Furthermore, other important factors that may preclude further transplantation individually or in combination should be identified, including fibrosis, mass(es), high intra-parenchymal fat content, calcification, edema, and/or significantly diseased arteries $[40,46,59]$. It is important to note that much of this assessment is highly subjective, and an "acceptable" pancreatic appearance and/or texture will vary from center-to-center. Obviously some of the co-factors such as high intra-parenchymal fat content, calcification, edema, and/ or significantly diseased arteries do not preclude the pancreas from being used for cellular transplantation. As an example, high intra-parenchymal fat content has been shown to be an advantage when performing islet isolation. Additionally, calcification, edema, and/or significantly diseased arteries do not affect the pancreas when used for islet cell isolation as all blood vessels and extraneous tissues are stripped from the pancreas prior to its use. The pancreas should not be discarded without direct consultation with the recipient team and exploration of its use for cellular transplantation if precluded from whole organ transplantation [9].

\subsubsection{Packaging the organ for transport}

Following perfusion, back-table dissection, and final inspection, the pancreas can then be packed into a suitable transport container along with perfusate solution to ensure ongoing exposure to cold preservation solution. Our unit uses the sterile triple plastic bag technique whereby the organ and a suitable volume of organ perfusion fluid is instilled into the first sterile plastic bag, without dilution from iced slush. All air is removed from the bag, prior to sealing it with a zip-tie or heavy tie. This bag is then placed inside a second sterile plastic bag filled with iced slush, ensuring close and adequate cooling of the perfusate-filled inner bag. These two bags are then placed inside a third sterile plastic bag that is securely sealed, double tied, and appropriately labeled to identify the organ and contents of the bags. Additional vessels retrieved for back-table reconstruction of the whole pancreas may also be packed into the triple sterile plastic bag set with the pancreas, or alternatively are placed inside a sterile vessel jar filled with preservation solution as per Figure 3, which is then double-bagged in sterile plastic bags, the first of which contains iced slush. The sealed pancreas and vessels are thence transported in a suitable, insulated iced shipping container. The container is labeled with its contents along with the contact details for both the donor and recipient coordinators.

\subsection{In situ perfusion and cold static preservation}

The function of in situ perfusion of the pancreas, as with other organs, is to achieve rapid removal of residual blood, whilst simultaneously cooling the organ and exposing it to preservation fluid media for subsequent cold static storage (CS). 


\subsubsection{Perfusion route}

In order to achieve adequate in situ pancreatic perfusion during abdominal organ perfusion as a whole, the aorta must be securely cannulated and flushed using pressure such that perfusion media can flow into the pancreas via the superior mesenteric, gastroduodenal, and splenic arteries. Once perfusion fluid has traversed the pancreas, it must be allowed to exit the donor's vasculature via the systemic and/or portal routes to prevent graft edema. Aortic-only perfusion is routinely performed by our center, and subsequent venous venting is usually undertaken via the IVC in the thorax. In the event that dual aorto-portal perfusion is employed for combined liver-pancreas retrievals, portal venous access via an inferior mesenteric cannula can impede pancreatic outflow, and reduce the physiologic arterial-portal pressure difference that is required for pancreatic perfusion/flow [42, 60]. As such, in these cases, the portal vein may instead be accessed after dividing it superior to the pancreas, thereby also allowing unobstructed pancreatic venous drainage via the proximal aspect of the transected portal vein [60,61]. A further back-table flush of the pancreas at the donor center is sometimes conducted via the splenic artery and SMA, although this step may be omitted [45, 62-65]. Evidence for or against either approach is currently lacking in both the case of whole pancreas and cellular transplantation. But preference in the cellular setting appears to favor not having any over-perfusion or edema as this can impede and dilute the infusion of the collagenase used for digestion of the pancreas in the isolation process [66].

\subsubsection{Perfusion fluid types}

In general, the same final fluid employed for the final in situ flush of the pancreas is then utilized for preservation of the organ in a bag of cold preservation fluid (CS). The preservation fluid utilized must maintain the organ at a hypothermic temperature $\left(0-4^{\circ} \mathrm{C}\right)$, whilst simultaneously ameliorating the consequences of cold ischemia and prolonged organ immersion in fluid. As such, cold organ preservation fluids should ideally have the following properties that aim to minimize and/or reverse cellular and subcellular processes occurring within the pancreas during CS:

- Disrupted ionic pumps and ion accumulation and/or depletion, with subsequent downstream effects;

- Mitochondrial dysfunction, including reversal of the electron transport chain, and succinate accumulation;

- Altered redox potentials (RP);

- Cellular edema;

- Acidosis;

- Accumulation of reactive oxygen species (ROS);

- Adenosine triphosphate (ATP) depletion; and,

- Disruption in glycolytic pathways [67-69]. 
There are multiple preservation fluids currently in existence. These can be broadly classified as those that are intracellular and extracellular/intermediate in nature, based largely upon the solution's potassium content, or low viscosity compared to high viscosity solutions [70]. Common components include colloid and/or impermeants to counteract cellular edema, antioxidants for protection against ROS generation, ATP precursors to allow replenishment upon reperfusion, and buffers to retard the acidosis attendant with organ ischemia [70].

University of Wisconsin (UW) solution remains the most popular pancreatic preservation fluid, and was initially developed specifically for this purpose [71]. It is an intracellular solution with a high potassium content and high viscosity as it contains hydroxyethyl starch, a particularly important component for pancreas preservation [24]. UW contains other components that fulfill many ideal criteria that should be exhibited by preservation fluids, including the addition of impermeants such as raffinose, the ATP precursor adenosine, and anti-oxidants such as allopurinol. [68] Histidine-tryptophan-ketoglutarate (HTK) is another commonly utilized preservation fluid for the pancreas. In contrast to UW, HTK it is an "intermediate" solution with a significantly lower potassium and sodium concentration, thereby in effect preventing ongoing organ metabolism. HTK also has low viscosity, theoretically allowing higher flow rates, and the histidine component of HTK provides it with significant buffering capacity $[68,70]$. The next most commonly studied and clinically utilized pancreas perfusion and preservation fluid is Celsior, which has similar potassium content to HTK in addition to containing histidine as a buffer. It differs from HTK in that it has much higher sodium content; furthermore, it incorporates some of the advantageous constituents of UW, including similar impermeants and one shared anti-oxidant [68, 70]. Most recently, the use of Institut Georges Lopez (IGL-1) solution has been reported in pancreatic transplantation [72]. This solution has similar constituents to UW, except the sodium and potassium concentrations are reversed such that it more closely resembles the extra-cellular environment [68]. A number of other more recently developed perfusion fluids have shown good effect in the preservation of pancreata for islet cell transplantation in particular the ET-Kyoto perfusion fluid. This fluid has a high sodium:low potassium ratio, and contains trehalose to protect the cell membrane against hypothermia and the nitric oxide donor nitroglycerin that facilitates vasodilatation [73].

National guidelines and/or protocols differ with respect to recommended perfusion and preservation fluids for the pancreas [45, 60, 74, 75]. UW and HTK solutions are the two most frequently recommended solutions for pancreas retrieval by such guidelines, although their utilization and volumes vary significantly. UK guidelines stipulate that in situ UW perfusion must be undertaken for pancreas retrieval, whilst Eurotransplant, German, and Australia/ New Zealand guidelines allow for either UW or HTK. Furthermore, none of these guidelines preclude dual perfusion when the pancreas is being retrieved, although German standards stipulate portal venous perfusion via a catheter inserted directly into the portal vein above the pancreas/duodenum [45, 60, 74, 75]. The use of Celsior or IGL-1 solution has not yet been incorporated into major National or Regional guidelines, although both have been employed in the clinical context $[64,65,72,76]$. 
A "pre-flush" is defined as a crystalloid fluid, such as Hartmann's solution, that is perfused in situ prior to the final flush/preservation fluid, such as UW. The pre-flush can be employed safely in pancreatic procurement, although it is not commonly utilized. The function of this pre-flush in the context of pancreas procurement is to potentially (1) reduce the amount of UW required, thereby reducing retrieval costs, and (2) to clear all blood from the vasculature such that any residual blood does not aggregate with the hydroxyethyl starch in UW [77, 78].

$\mathrm{UW}$ is traditionally perfused in much lower volumes in comparison to HTK, and this is also reflected in the various pancreas retrieval guidelines in existence. This is largely related to the higher viscosity of UW, in addition to the larger volume and time for HTK perfusion to achieve equilibration of electrolyte content with the extracellular milieu [79, 80]. Australian guidelines recommend a 2-4 L crystalloid/low viscosity solution in situ pre-flush, followed by a UW flush of at least 1-2 L; a volume range for HTK is not specified [45]. In contrast, UK guidelines state a UW flush of $50-70 \mathrm{ml} / \mathrm{kg}$ should be employed via the aorta, whilst Eurotransplant allows for 50-100 ml/kg UW or 150-300 ml/kg HTK [74, 75]. Published reports may deviate from this; perfusion volumes utilized in aortic-only perfusion range from $0.8-$ 5.6 L, 4.9-9.7 L, and 0.8-7.9 L for UW, HTK, and Celsior respectively [81].

\subsubsection{Additive(s) to perfusate}

Heparin is a standard additive to the in situ perfusion fluid during DCD organ retrievals, including for the pancreas. Additionally, thrombolytics such as streptokinase or tissue plasminogen activator (tPA) can be added to the in situ perfusion fluid, or alternatively our approach is to directly inject tPA into the aorta before commencement of the cold in situ flush; the aim of this is to achieve a higher quality vascular flush through the clearance of microthrombi [82-84]. However no comparative evidence exists for or against the use of thrombolytics in DCD pancreas retrieval, although there is certainly enthusiasm for this approach $[83,85]$.

\subsubsection{Two-layer method}

Great focus has remained on improving the quality of pancreas transport to the islet transplant centers, including novel ways to provide oxygen rich media to the graft whilst in cold storage during shipping. In late 1988 Kuroda et al. was the first to report the use of the TwoLayer Method (TLM) for shipping of the pancreas prior to islet cell isolation [86]. The TLM uses a perfluorochemical (PFC) and the organ perfusion fluid; initially Euro-Collins' solution was used but was replaced by UW solution. The benefits of the use of the PFC are due to it being a biologically inert liquid that acts as an oxygen-supplying media. A pancreas preserved using the TLM is theoretically oxygenated through the PFC and substrates are supplied by the UW solution. This allows the pancreas preserved using the TLM to generate adenosine triphosphate during storage, prolonging the preservation time [87]. Strong debate still remains over its benefits, if any, when compared to the use of UW solution during CS $[88,89]$ and a recent publication of guidelines recommended against the use of the TLM for preservation of the pancreas preceding islet isolation [85]. 


\section{Outcomes}

\subsection{Whole organ pancreas transplant outcomes}

Vascularized pancreas transplantation outcomes have improved considerably over time. Although changes to immunosuppression and post-transplantation care can partly account for this, advances in retrieval surgery and organ preservation, in addition to better donor selection, are significant contributors $[90,91]$. When exploring pancreas transplantation outcomes, it is paramount to account for the type of transplant performed, as these are associated with differential graft success and survival rates. More specifically, outcomes must be considered based on whether a simultaneous pancreas-kidney (SPK), pancreas after kidney (PAK) transplant, or pancreas transplant alone (PTA) was performed. An exploration of general pancreas transplantation outcomes is beyond the scope of this chapter, as the focus is on the specific impact of retrieval and preservation practices. Overviews investigating trends and recipient outcomes following pancreas transplantation have been published by others, including Dean et al., and Gruessner et al. [90-94]. In brief, the current expected 5-year graft and patient survival rates for pancreas (SPK) transplantation range from 73 to $82 \%$ and 89 to $93 \%$, respectively, in the US, UK, Eurotransplant region, and Australia/New Zealand [91, 94-96]. Outcome differences are seen between SPKs, which have historically provided better results, and PTAs and PAKs, due to important variations in the type(s) of recipients for each transplant type, technical differences in the transplantation procedure, and a differential ability to diagnose and treat rejection episodes [91]. SPK transplantation is by far the most commonly performed type of pancreas transplant but islet cell transplantation has also seen a great increase in acceptance and success.

\subsection{Islet cell transplant outcomes}

Like its forebear, islet cell transplantation outcomes have improved considerably over time. The most impactful change was seen with advances in immunosuppression, clearly shown by the success of the Edmonton trial [97], one that revolutionized the progress of the cellular transplant. Other factors have also continued to impact the field, including post-transplantation care, advances in retrieval surgery and organ preservation, in addition to better donor selection. In brief, the most recent presentation from the Collaborative Islet transplant registry (CITR), presented the combined world islet cell transplant data where they reported that over 1055 allogeneic islet transplants have now been reported by 50 islet transplantation centers in Australia, Europe, North America, and Asia. Of these cases, islet transplant alone (ITA) was the most frequent procedure $(\mathrm{n}=858)$ followed by islet after kidney (IAK) and simultaneous islet and kidney transplantation (SIK) $(n=197)$ [98]. More recently, according to outcomes of the Phase 3 Trial of Transplantation of Human Islets in Type 1 Diabetes Complicated by Severe Hypoglycemia, the primary end point of $\mathrm{HbA} 1 \mathrm{c}<7.0 \%$ was achieved by $87.5 \%$ of subjects at 1 year and by $71 \%$ at 2 years. The median $\mathrm{HbA} 1 \mathrm{c}$ level was $5.6 \%$ at both 1 and 2 years. Hypoglycemia awareness was restored, with highly significant improvements in Clarke and HYPO scores $(\mathrm{P}>0.0001)$. No study-related deaths or disabilities occurred [99]. This trial clearly demonstrated the significant improvements achieved in the outcomes of islet cell transplantation and its impact on those patients suffering from hypoglycemic unawareness. 


\subsection{The impact of procurement practices and techniques}

Pancreas procurement techniques can significantly impact subsequent transplantation outcomes, and can also prove the difference between organ utilization and discard. In particular, there is ample evidence that factors such as en bloc retrieval, retrieval technique and graft handling, type(s) of instruments utilized, and perfusion routes are all important determinants of graft function and transplant-related morbidity. Ensuring that pancreas retrieval is performed by an experienced pancreatic transplant surgeon can significantly minimize such retrieval-related complications and risks [100].

Pancreatic damage during retrieval is not uncommon, and may deem the organ unusable certainly for whole organ transplant. Although the rates are different between centers and of course depends upon the level of training of the surgeons performing the retrievals, a large UK registry analysis showed a greater than $50 \%$ rate of surgical damage in retrieved pancreata; furthermore, approximately $10 \%$ of grafts were subsequently discarded due to damage sustained at retrieval in this analysis [37]. This was further seen as a significant loss as the grafts were also not utilized for islet cell transplantation due to extended cold ischemic times as a result of ongoing referrals. Within the same series, parenchymal and/or vascular (arterial) damage at procurement contributed to significantly higher rates of subsequent graft loss if the pancreas proceeded to transplantation [37]. In order to minimize surgical retrieval damage it is best to ensure that the staff performing the surgery are at a more senior level, and therefore our unit always sends a senior experienced surgeon to all pancreas retrieval surgeries to ensure adequate training of junior staff and optimize graft quality.

Graft thrombosis is the most important technical cause of whole organ pancreatic allograft loss. Pancreas retrieval and surgical technique is a significant etiologic factor in the incidence of graft thrombosis [101-104]. Graft pancreatitis, which in itself is a significant risk factor for graft thrombosis, is another potentially catastrophic complication associated with morbidity and graft loss that is partly attributable to retrieval technique [100]. Excessive graft handling and poor retrieval surgical technique, including damage to the inferior pancreaticoduodenal artery, are commonly accepted causes of graft pancreatitis in the recipient. [100] The same contributing factors also have an impact on the organs when they are used for islet cell isolation [9].

En bloc procurement of the liver and pancreas is associated with better recipient outcomes owing to faster organ retrieval and therefore shorter warm ischemia times [58, 100]. Interestingly, in the aforementioned UK registry analysis between 2008 and 2012, although the vast majority of liver and pancreas retrievals were not performed en bloc, there was a trend favoring the en bloc approach with respect to reduced pancreatic retrieval injury [37].

In situ perfusion routes, in particular the utilization of dual aorto-portal perfusion in preference to aortic-only perfusion, can impact both whole organ and cellular allograft outcomes. Dual perfusion is potentially associated with increased retrieval-related pancreatic injury through a combination of flush injury (increased perfusion volumes), and/or an obstruction of pancreatic portal venous outflow secondary to catheter placement within the inferior or superior mesenteric veins $[52,58]$. This ultimately impacts on the pancreas that is retrieved for whole pancreas or cellular transplantation as it can cause a significant increase in edema, and 
may be associated with a higher rate of graft pancreatitis in whole organ, and poorer isolation results due to collagenase dilution in the islet isolation process. Importantly, an aortic-only perfusion technique does not seem to compromise hepatic allograft outcomes, especially in the standard criteria DBD donors from which pancreata are usually retrieved, and therefore should be considered by retrieval surgeons in these circumstances especially in centers that retrieve grafts for both whole and cellular transplantation [34, 58].

Furthermore, the specific instrument-type employed for pancreatic dissection is an important determinant of the amount of pancreatic bleeding upon reperfusion in the recipient [46]. We have shown that ultrasonic shear (e.g. Harmonic Scalpel) utilization during pancreas retrieval allows the sealing of peri-pancreatic vessels that are otherwise easily missed, thereby contributing to less bleeding and a reduced blood transfusion requirement after transplantation within the recipient [41].

\subsection{The impact of perfusion and preservation fluids}

Pancreas preservation by cold storage using University of Wisconsin solution has been the mainstay method used for pancreas transplantation over the past two decades. Other solutions, such as HTK, Celsior, and SCOT 15, struggled to demonstrate any advantage for shortterm preservation periods. But the advent of clinical islet transplantation and the larger use of controlled DBD donors have prompted the transplantation community to develop methods for increasing pancreas graft quality while preventing ischemic reperfusion damage especially in the cellular arena. It has been thought that oxygenation by 1- or 2-layer methods during pancreas preservation, as well as the use of perfluorocarbons, may increase islet yield. Based on the former methods, there is a renewed interest in machine perfusion and oxygenation in pancreas preservation for pancreas transplantation and islet cell preparation [105].

A recent systematic review and meta-analysis by our group compared the outcomes of whole organ pancreas transplantation based on the in situ perfusion and subsequent preservation fluid utilized (UW, HTK, or Celsior) [81]. Ischemia-reperfusion injury of the pancreas, as reflected by post-operative peak lipase levels, was significantly lower when UW was employed as a perfusion/preservation fluid in comparison to HTK, but there was no significant difference in peak amylase. This pancreatic ischemia-reperfusion injury may translate to lower clinical graft pancreatitis rates when UW is used in comparison to HTK, although this is not a universal finding [106]. No significant disparity was observed in biochemical injury markers or graft pancreatitis rates between UW and Celsior [81].

As discussed above, post-transplantation graft thrombosis is a significant cause of graft loss. Thrombotic graft loss rates do not differ based on whether UW, HTK, or Celsior is used for in situ perfusion and preservation of the pancreas [81]. Furthermore, cumulative graft survival after first post-transplantation month does not favor UW over HTK, although a distinct trend favoring UW emerges at the 1-year mark [81, 106, 107]. A US registry analysis provided further evidence for this, showing a significant association between HTK perfusion/preservation and graft loss, in comparison to UW [108]. In comparison, the use of Celsior is associated with similar 1-year graft survival rates to UW $[64,76]$. 
The comparative utility of each preservation fluid must also be considered in the context of additional donor and transplant-related factors. One important consideration when considering any possible superior preservation effects of UW is the expected pancreatic graft cold ischemic time (CIT). UW may especially be beneficial when CIT is greater than or equal to 12 hours [106, 108]. Furthermore, as already mentioned previously, pancreas retrieval is usually undertaken in the multi-organ donor setting. The perfusion/preservation fluid utilized must therefore not compromise any abdominal organ additionally procured, especially the liver. There is conflicting evidence regarding the relative efficacy of UW, HTK, Celsior, and IGL-1 for liver preservation. Some authors suggest that HTK results in inferior graft survival in comparison to UW, whilst others have reported similar survival but a reduction in postliver transplantation biliary strictures when HTK is utilized [109, 110]. Overall, current cumulative evidence does not suggest a significant difference between these four fluids, and further research in this area is required [34].

\subsection{Donation after circulatory death (DCD) vs. donation after brain death (DBD) transplantation and the importance of donor selection}

With careful selection of donors, excellent whole organ pancreatic transplantation outcomes can be obtained even after DCD transplantation. The Pancreas Donor Risk Index (PDRI) is a tool that incorporates donor and preservation-related risk factors, including DCD donors, prolonged preservation time, and high body mass index (BMI), in a risk model for subsequent graft failure [111]. This model has been utilized in both the North American and European settings [111, 112]. It is important to note however that such models must not be used in isolation, and donor pancreata with one or more risk factors, including DCD donors, can still be used to achieve good outcomes. Indeed, our center's first DCD pancreas transplant was in 2007, and has been followed by a further six DCD pancreas transplants, all displaying good long-term graft function [84, 113]. Meta-analyses have shown equivalent graft and patient survival when comparing DBD and DCD pancreatic transplantation, although graft thrombosis rates are higher when DCD grafts are used [51, 114]. Importantly, this higher graft thrombosis rate can be abrogated when donor therapies such as systemic ante-mortem heparin administration are applied [51]. The use of younger donors, with a lower BMI, and low warm ischemic times, has contributed to the success of DCD whole organ pancreas transplantation $[84,115]$.

There has, however, been more reserved interest in DCD in pancreas for cellular transplantation as the perceived ischemic insult appears to have a much greater effect on the isolated islets for cellular transplantation than when the whole pancreas is transplanted. This is largely because the entire reserve of islets remains intact in the whole organ graft rather than being removed, and a smaller proportion is transplanted in the cellular graft [66, 99]. However, a number of encouraging studies have shown varying success. Albeit from a more advantageous DCD setting allowing earlier intervention including cannulation of the donor and antemortem heparin administration, which has, been shown to be a distinct advantage in this setting [51]. One such report from the Japanese Islet Registry reported their findings from 65 DCD islet isolations performed for 34 transplantations in 18 patients with T1DM. Despite 
the fact that all recipients remained free of severe hypoglycemia, only three patients achieved insulin independence for 14, 79, and 215 days. HbA1c levels and requirement of exogenous insulin were significantly improved in all patients [116]. In the more traditional DCD setting the Edmonton group have recently reported their findings comparing islet isolations from 15 DCD and 418 DBD donors performed between September 2008 and September 2014. Compared to DBD, pancreata from DCD were procured locally and donors required less vasopressive support $(\mathrm{P}<0.001$ and $\mathrm{P}=0.023$, respectively), but the other variables were similar between groups. The metabolic function was similar between DBD and DCD, as well as the mean decrease in insulin requirement at 1-month post-transplantation (DBD: $64.82 \%$; DCD: $60.17 \%$ reduction, $\mathrm{P}=0.517)$. These results support the broader use of DCD pancreata for islet isolation. However, a much larger DCD islet experience will be required to truly determine non-inferiority of both short and long-term outcomes [117].

\section{Future perspectives}

There has been considerable interest regarding the utility and advantages of dynamic preservation methods in comparison to CS alone for organs such as the liver, kidneys, heart, and lungs. The pancreas has not remained immune to attempts adapting such techniques during the post-procurement phase, although their current clinical success remains limited. Nonstatic methods of preservation can potentially:

- Reduce graft discard by allowing more accurate graft assessment after retrieval in comparison to current methods, which are largely subjective; and

- Improve organ quality by reducing ischemia-reperfusion-related damage, including by the targeted delivery of pharmacotherapies aimed against ischemia-reperfusion injury, and also gene therapies and stem cells, into the pancreas.

\subsection{Machine perfusion}

Machine (ex vivo) perfusion (MP) entails cannulation and mechanical perfusion of the pancreas via its inflow vessels; perfusion fluid is re-circulated through the circuit for the duration of perfusion. Broadly, MP can be hypothermic, subnormothermic or normothermic, pulsatile or non-pulsatile, and continuous or for a limited proportion of the preservation/transport phase (e.g. pre-implantation). Current pancreatic MP work is lacking in the sphere of clinical transplantation, and is limited to pre-clinical animal and discarded human pancreas studies; only the latter will be the focus of this section, with experimental animal work summarized in detail elsewhere [118-120].

There are certain pancreas-specific issues that need to be considered with respect to MP that do not apply to other organs such as the kidney. Most importantly, the pancreas is a low-flow organ, and even relatively low pressures in a MP setup can result in significant graft edema and weight gain [121]. Furthermore, higher perfusion pressures can contribute to vascular thrombosis secondary to endothelial damage [120]. However, especially if MP is undertaken 
at normal body temperature (normothermic), such risks must then be balanced against the need for adequate perfusion to sustain normal aerobic metabolism. An additional challenge during pancreatic MP is the need to adequately and safely account for the organ's exocrine output, which is stimulated during normothermic perfusion [122].

As a result of these issues, most pancreatic MP studies have been conducted in the field of islet cell transplantation rather than the whole pancreas [120, 123]. Graft edema, is disadvantageous for both whole organ and cellular transplantation. However some groups have studied its use as it theoretically facilitates the enzymatic digestion of pancreatic acinar tissue [124]. Hypothermic MP can potentially be employed to increase human islet yield, viability, and insulin secretion despite an extended CIT (> 12 hours), possibly increasing the number of pancreata that can be used for successful islet isolation [125]. Cases of human islet transplantation following MP are yet to be published, however. Whole organ pancreas MP has been investigated in the context of extended criteria organs that were not utilized for human transplantation. Some authors have shown 6 hours of oxygenated hypothermic MP using UW machine perfusion solution increases the ATP content of DCD pancreata to reach a level that is similar to DBD pancreata at baseline [126]. Graft edema can be kept to a minimum if low pressure hypothermic MP is utilized, even for as long as 24 hours [127]. Subsequent ex vivo normothermic perfusion can be used to simulate reperfusion at transplantation after initial hypothermic MP, and has been shown to demonstrate adequate insulin secretion by such pancreata [128].

Normothermic MP is an attractive alternative for whole pancreas preservation, and likely provides better graft viability assessment than hypothermic perfusion. Both endocrine and exocrine graft function can be assessed during perfusion by measuring C-peptide and/or insulin secretion and stimulation in response to glucose, and amylase and lipase release, respectively $[122,129]$. Blood flow and resistance parameters can also be assessed using this technique, although this is also possible with hypothermic MP. However it is important to note that no defined cut-offs or validated protocols for human transplantation have been developed, and will require significantly more pre-clinical work.

\subsection{Persufflation}

Persufflation is a technique in which the pancreas is directly perfused with a humidified gas such as oxygen via the SMA and/or splenic arteries. Non-utilized human DBD pancreata have been perfused by this method, and subsequent graft assessment showed an increase in pancreatic ATP levels [130]. Porcine data from the same group showed significantly improved pancreatic histology after 24 hours of persufflation in comparison to utilization of the TLM [131]. Islet isolation after 24 hours of persufflation, including in human pancreata, is likely increased, compared to other methods such as the TLM [132]. This was confirmed in a later study, whereby islets of sufficient quantity and quality for transplantation were isolated from all five human pancreata that underwent persufflation using $40 \%$ humidified oxygen perfused at 10-25 mmHg [133]. Similar to MP however, pancreas persufflation has not yet been followed by clinical islet and/or whole organ pancreas transplantation although some research is now underway by a limited number of groups. 


\subsection{Normothermic regional perfusion}

Normothermic Regional Perfusion (NRP) of the abdomen was initially utilized in Spain in the uncontrolled DCD setting, and has since been utilized in the controlled DCD setting in other European countries and Asia [134-138]. The donor's systemic arterial and venous systems are rapidly cannulated, and an ex vivo pump/oxygenator system is used to maintain an effective artificial circulation of the abdominal viscera. Cerebral and thoracic perfusion is avoided by clamping the supra-celiac aorta. This system reduces the organ's warm ischemic insult, and proposed benefits include facilitation of a more effective subsequent in situ cold flush, ATP replenishment, and reduced oxidative stress [139]. Current experience for NRP exists mainly in the sphere of kidney and liver transplantation. However, utilization of this technique for DCD pancreas preservation and transplantation is appealing, especially because DCD pancreata can have sustained, long-term graft function (as discussed above). Within the UK, five pancreata have been procured after initial NRP, resulting in two SPK transplants and one islet cell transplantation [136]. In Spain, one NRP pancreas has been transplanted in the context of a controlled DCD donor [140]. Future studies are required to more effectively classify evidence for this strategy, and define its comparative role or efficacy with respect to MP. In the DCD setting, NRP may prove to be a more feasible strategy than MP owing to the aforementioned difficulties of maintaining a pancreas on an ex vivo machine circuit, although no direct comparisons exist between the two methods.

\section{Conclusions}

This chapter outlines the numerous advances that have occurred over the past few decades in pancreas retrieval techniques for both whole organ and cellular transplantation. It clearly demonstrates the improved outcomes in both whole pancreas and islet cell transplantation from significant improvements to organ donor selection and management, and organ perfusion and retrieval surgery. We have seen insulin independence rates for more than 10 years post-transplant in both settings with minimal complications. Whole organ transplantation is obviously now a well-accepted clinical therapy for many patients worldwide. However, islet transplantation still has limited application to the broader population of patients with T1D due to its reliance on the availability of cadaveric donors and selection, isolation results and transplant engraftment, the side effects of immunosuppression and issues associated with the requirement for lifelong immunosuppression. The future holds many interesting potential new therapies that may or may not yield appropriate and safe methods for treatment of type 1 diabetes. From what has been outlined in this chapter we can see that outcomes for patients have improved significantly. If, unfortunately, patients cannot be treated prior to the advent of their type 1 diabetes then they can still be treated by transplantation. Moving forward, researchers and clinicians have numerous fronts and multiple strategies arising at different stages of development in which to be able to offer patients treatments tailored to them and their disease. In the foreseeable future, transplantation and in particular the focus on organ retrieval and organ preservation will play a significant role in further improving outcomes, particularly with newer technologies such as machine perfusion and normothermic regional perfusion. Such technologies are hoped to increase both the 
number of suitable whole pancreata, as well as their quality, which will simultaneously lead to improved islet cell numbers and function in the cell therapy sphere of Diabetes care.

\section{Acknowledgements}

The authors wish to thank Callista Rainey for assistance with the figures in this chapter. The authors also wish to acknowledge support from the Royal Australasian College of Surgeons (Sir Roy McCaughey Surgical Research Fellowship).

\section{Conflicts of interest}

The authors declare no conflicts of interest.

\section{Abbreviations}

BMI body mass index

CS Celsior

CIT cold ischemic time

DBD donation after brain death

DCD donation after circulatory death

PFC perfluorochemical

T1D type 1 diabetes

UW solution University of Wisconsin

SPK simultaneous pancreas and kidney

TLM two-layer method

T1D type 1 diabetes

\section{Author details}

Wayne J. Hawthorne ${ }^{1,2,3 *}$, Ahmer Hameed ${ }^{1,2,3}$ and Henry Pleass ${ }^{1,3}$

*Address all correspondence to: wayne.hawthorne@sydney.edu.au

1 Department of Surgery, Westmead Hospital, Sydney, Australia

2 Centre for Transplant and Renal Research, Westmead Institute for Medical Research, Sydney, Australia

3 Sydney Medical School, University of Sydney, Sydney, Australia 


\section{References}

[1] Squifflet JP, Gruessner RW, Sutherland DE. The history of pancreas transplantation: Past, present and future. Acta Chirurgica Belgica. 2008;108:367-378

[2] SutherlandDE, Najarian JS. Transplantation of the pancreas. Transplantation Proceedings. 1979;11:1158-1162

[3] Barton FB, Rickels MR, Alejandro R, Hering BJ, Wease S, Naziruddin B, et al. Improvement in outcomes of clinical islet transplantation: 1999-2010. Diabetes Care. 2012;35:1436-1445. DOI: $10.2337 /$ dc12-0063

[4] Squifflet JP. The history of transplantation at the Catholic University of Louvain-Belgium 1963-2003. Acta Chirurgica Belgica. 2003;103(Suppl 1):10-20. DOI: 10.1080/00015458.2003. 11679382

[5] A definition of irreversible coma. Report of the ad hoc committee of the Harvard Medical School to examine the definition of brain death. Journal of the American Medical Association. 1968;205:337-340

[6] Bell MD. Non-heart beating organ donation: Old procurement strategy--new ethical problems. Journal of Medical Ethics. 2003;29:176-181

[7] Hawthorne WJ. Necessities for a clinical islet program. Advances in Experimental Medicine and Biology. 2016;938:67-88. DOI: 10.1007/978-3-319-39824-2_6

[8] O'Gorman D, Kin T, Murdoch T, Richer B, McGhee-Wilson D, Ryan E, et al. The standardization of pancreatic donors for islet isolation. Transplantation Proceedings. 2005;37: 1309-1310. DOI: 10.1016/j.transproceed.2004.12.087

[9] Farney ACSD, Opara EC. Evolution of islet transplantation for the last 30 years. Pancreas. 2016;45:8-20. DOI: 10.1097/MPA.0000000000000391

[10] Bertuzzi FAB, Tosca MC, Galuzzi M, Bonomo M, Marazzi M, Colussi G. Islet transplantation in pediatric patients: Current indications and future perspectives. Endocrine Development. 2016;30:14-22. DOI: 10.1159/000439322

[11] Starzl TE. Experience in Renal Transplantation. Philadelphia: WB Saunders Co.; 1964

[12] Gwathmey O, Pierpont H. Stage occlusion and resection of the human aortic arch with hypothermia. The American Surgeon. 1955;21:827-834

[13] Owens JC, Prevedel AE, Swan H. Prolonged experimental occlusion of thoracic aorta during hypothermia. A.M.A. Archives of Surgery. 1955;70:95-97

[14] Marchioro TL, Huntley RT, Waddell WR, Starzl TE. Extracorporeal perfusion for obtaining postmortem homografts. Surgery. 1963;54:900-911

[15] Belzer FO, Ashby BS, Dunphy JE. 24-hour and 72-hour preservation of canine kidneys. Lancet. 1967;2:536-538

[16] Starzl TE. History of clinical transplantation. World Journal of Surgery. 2000;24:759-782 
[17] Collins GM, Bravo-Shugarman M, Terasaki PI. Kidney preservation for transportation. Initial perfusion and 30 hours' ice storage. Lancet. 1969;2:1219-1222

[18] Ackermann JR, Snell ME. Cadaveric renal transplantation: A technique for donor kidney removal. British Journal of Urology. 1968;40:515-521

[19] Merkel FK, Jonasson O, Bergan JJ. Procurement of cadaver donor organs: Evisceration technique. Transplantation Proceedings. 1972;4:585-589

[20] Benichou J, Halgrimson CG, Weil R 3rd, Koep LJ, Starzl TE. Canine and human liver preservation for 6 to $18 \mathrm{hr}$ by cold infusion. Transplantation. 1977;24:407-411

[21] de Gruyl J, Westbroek DL, Macdicken I, Ridderhof E, Verschoor L, van Strik R. Cryoprecipitated plasma perfusion preservation and cold storage preservation of ductligated pancreatic allografts. The British Journal of Surgery. 1977;64:490-493

[22] Wall WJ, Calne RY, Herbertson BM, Baker PG, Smith DP, Underwood J, et al. Simple hypothermic preservation for transporting human livers long distances for transplantation. Report of 12 cases. Transplantation. 1977;23:210-216

[23] Kalayoglu M, Sollinger HW, Stratta RJ, D'Alessandro AM, Hoffmann RM, Pirsch JD, et al. Extended preservation of the liver for clinical transplantation. Lancet. 1988;1:617-619

[24] Ploeg RJ, Boudjema K, Marsh D, Bruijn JA, Gooszen HG, Southard JH, et al. The importance of a colloid in canine pancreas preservation. Transplantation. 1992;53:735-741

[25] Belzer FO, Southard JH. Principles of solid-organ preservation by cold storage. Transplantation. 1988;45:673-676

[26] Starzl TE, Hakala TR, Shaw BW Jr, Hardesty RL, Rosenthal TJ, Griffith BP, et al. A flexible procedure for multiple cadaveric organ procurement. Surgery, Gynecology \& Obstetrics. 1984;158:223-230

[27] Starzl TE, Miller C, Broznick B, Makowka L. An improved technique for multiple organ harvesting. Surgery, Gynecology \& Obstetrics. 1987;165:343-348

[28] Deane SA, Ekberg H, Stewart GJ, Grierson JM, Williamson P, Hawthorne W, et al. Whole pancreas grafting with exocrine drainage into the bladder: Method of choice for clinical transplantation? Transplantation Proceedings. 1988;20:84-86

[29] Ekberg H, Deane SA, Allen RDM, Hawthorne WJ, Williamson P, Grierson JM, et al. Monitoring of canine pancreas allograft function with measurements of urinary amylase. ANZ Journal of Surgery. 1988;58:583-586. DOI: 10.1111/j.1445-2197.1988.tb06198.x

[30] Deane SA, Ekberg H, Stewart GJ, Grierson JM, Williamson P, Hawthorne WJ, et al. Canine whole pancreatic transplantation with exocrine drainage into the bladder. ANZ Journal of Surgery. 1989;59:659-664

[31] Griffin AD, Hawthorne WJ, Allen RD, Grierson JM, Jablonski P, Howden BO, et al. Twenty-four-hour preservation of canine pancreas allografts using low-cost, lowviscosity, modified University of Wisconsin cold storage solution. Transplantation Proceedings. 1993;25:1595-1596 
[32] Wilson TG, Hawthorne WJ, Lau H, Williamson P, ChapmanJR, Grierson JM, et al. Pretreatment of canine whole pancreas allografts with monoclonal antibodies does not prolong graft survival. Transplantation Proceedings. 1990;22:2163-2164

[33] Lam VW, Pleass HC, Hawthorne W, Allen RD. Evolution of pancreas transplant surgery. ANZ Journal of Surgery. 2010;80:411-418. DOI: 10.1111/j.1445-2197.2010.05309.x

[34] Hameed AM, Laurence JM, Lam VWT, Pleass HC, Hawthorne WJ. A systematic review and meta-analysis of cold in situ perfusion and preservation of the hepatic allograft: Working toward a unified approach. Liver Transplantation. 2017;23:1615-1627. DOI: 10.1002/lt.24829

[35] Greenwald MA, Kuehnert MJ, Fishman JA. Infectious disease transmission during organ and tissue transplantation. Emerging Infectious Diseases. 2012;18. DOI: 10.3201/ eid1808.120277

[36] Martinez-Pourcher V. Infections in the transplant patient. La Revue du Praticien. 2015;65:1075-1078

[37] Ausania F, Drage M, Manas D, Callaghan CJ. A registry analysis of damage to the deceased donor pancreas during procurement. American Journal of Transplantation. 2015;15:29552962. DOI: $10.1111 /$ ajt.13419

[38] Allen RD, Nankivell BJ, Hawthorne WJ, O'Connell PJ, Chapman JR. Pancreas and islet transplantation: An unfinished journey. Transplantation Proceedings. 2001;33:3485-3488

[39] Allen RD, Chapman JR, Hawthorne WJ, Pearl TA, Wilson TG, Lau H, et al. Advantages and disadvantages of pancreas transplantation. Transplantation Proceedings. 1992;24:171-172

[40] Fridell JA, Powelson JA, Kubal CA, Burke GW, Sageshima J, Rogers J, et al. Retrieval of the pancreas allograft for whole-organ transplantation. Clinical Transplantation. 2014;28:13131330. DOI: $10.1111 /$ ctr.12459

[41] Hameed A, Yu T, Yuen L, Lam V, Ryan B, Allen R, et al. Use of the harmonic scalpel in cold phase recovery of the pancreas for transplantation: The westmead technique. Transplant International. 2016;29:636-638. DOI: 10.1111/tri.12777

[42] Forsythe JL. In: Garden OJ, Paterson-Brown S, editors. A Companion to Surgical Practice: Transplantation. 5th ed. Saunders Elsevier: Edinburgh; 2014

[43] Olson DW, Kadota S, Cornish A, Madsen KL, Zeng J, Jewell LD, et al. Intestinal decontamination using povidone-iodine compromises small bowel storage quality. Transplantation. 2003;75:1460-1462. DOI: 10.1097/01.tp.0000060871.02234.1b

[44] Thwaites SE, Lam VWT, Yao J, Kable K, Jenkins L, Chen C, et al. Surgical morbidity of simultaneous kidney and pancreas transplantation: A single-Centre experience in the Tacrolimus era. ISRN Transplantation. 2013;2013(6). DOI: 10.5402/2013/685850

[45] TSANZ. Guidance Document - Surgical Technique for Deceased Donor Abdominal Organ Procurement (ATCA-TSANZ Guidelines G003/2015). Sydney, Australia: TSANZ; 2015

[46] Oniscu GC, Forsythe JLR, Fung JJ. Abdominal Organ Retrieval and Transplantation Bench Surgery. Chichester, West Sussex: John Wiley \& Sons; 2013 
[47] Thwaites SE, Gurung B, Yao J, Kable K, Robertson P, Ryan BJ, et al. Excellent outcomes of simultaneous pancreas kidney transplantation in patients from rural and urban Australia: A national service experience. Transplantation. 2012;94:1230-1235. DOI: 10. 1097/TP.0b013e3182708e04

[48] Jeon H, Ortiz JA, Manzarbeitia CY, Alvarez SC, Sutherland DE, Reich DJ. Combined liver and pancreas procurement from a controlled non-heart-beating donor with aberrant hepatic arterial anatomy. Transplantation. 2002;74:1636-1639. DOI: 10.1097/01.tp. 0000038707.82035.75

[49] Reich DJ, Mulligan DC, Abt PL, Pruett TL, Abecassis MM, D'Alessandro A, et al. ASTS recommended practice guidelines for controlled donation after cardiac death organ procurement and transplantation. American Journal of Transplantation. 2009;9:2004-2011. DOI: 10.1111/j.1600-6143.2009.02739.x

[50] D’Alessandro AM, Hoffmann RM, Knechtle SJ, Eckhoff DE, Love RB, Kalayoglu M, et al. Successful extrarenal transplantation from non-heart-beating donors. Transplantation. 1995;59:977-982

[51] Shahrestani S, Webster AC, Lam VW, Yuen L, Ryan B, Pleass HC, et al. Outcomes from pancreatic transplantation in donation after cardiac death: A systematic review and meta-analysis. Transplantation. 2017;101:122-130. DOI: 10.1097/tp.0000000000001084

[52] Nghiem DD, Cottington EM. Pancreatic flush injury in combined pancreas-liver recovery. Transplant International. 1992;5:19-22

[53] Dunn DL, Morel P, Schlumpf R, Mayoral JL, Gillingham KJ, Moudry-Munns KC, et al. Evidence that combined procurement of pancreas and liver grafts does not affect transplant outcome. Transplantation. 1991;51:150-157

[54] D'Alessandro AM, Reed A, Hoffmann RM, Sollinger HW, Kalayoglu M, Knechtle SJ, et al. Results of combined hepatic, pancreaticoduodenal, and renal procurements. Transplantation Proceedings. 1991;23:2309-2311

[55] Conway MB, Saunders R, Munn SR, Perkins JD. Combined liver/pancreaticoduodenal procurement effect on allograft function. Transplantation Proceedings. 1990;22:429-430

[56] Spees EK, Orlowski JP, Temple DR, Kam I, Karrer IF. Efficacy of simultaneous cadaveric pancreas and liver recovery. Transplantation Proceedings. 1990;22:427-428

[57] Abu-Elmagd K, Fung J, Bueno J, Martin D, Madariaga JR, Mazariegos G, et al. Logistics and technique for procurement of intestinal, pancreatic, and hepatic grafts from the same donor. Annals of Surgery. 2000;232:680-687

[58] Brockmann JG, Vaidya A, Reddy S, Friend PJ. Retrieval of abdominal organs for transplantation. The British Journal of Surgery. 2006;93:133-146. DOI: 10.1002/bjs.5228

[59] Maglione M, Ploeg RJ, Friend PJ. Donor risk factors, retrieval technique, preservation and ischemia/reperfusion injury in pancreas transplantation. Current Opinion in Organ Transplantation. 2013;18:83-88. DOI: 10.1097/MOT.0b013e32835c29ef 
[60] Wunderlich H, Brockmann JG, Voigt R, Rauchfuss F, Pascher A, Brose S, et al. DTG procurement guidelines in heart beating donors. Transplant International. 2011;24:733-757. DOI: 10.1111/j.1432-2277.2011.01266.x

[61] Sollinger HW, Vernon WB, D'Alessandro AM, Kalayoglu M, Stratta RJ, Belzer FO. Combined liver and pancreas procurement with Belzer-UW solution. Surgery. 1989;106:685-690 discussion 690-681

[62] Potdar S, Malek S, Eghtesad B, Shapiro R, Basu A, Patel K, et al. Initial experience using histidine-tryptophan-ketoglutarate solution in clinical pancreas transplantation. Clinical Transplantation. 2004;18:661-665. DOI: 10.1111/j.1399-0012.2004.00262.x

[63] Fridell JA, Mangus RS, Powelson JA. Histidine-tryptophan-ketoglutarate for pancreas allograft preservation: The Indiana University experience. American Journal of Transplantation. 2010;10:1284-1289. DOI: 10.1111/j.1600-6143.2010.03095.x

[64] Boggi U, Vistoli F, Del Chiaro M, Signori S, Croce C, Pietrabissa A, et al. Pancreas preservation with University of Wisconsin and Celsior solutions: A single-center, prospective, randomized pilot study. Transplantation. 2004;77:1186-1190

[65] Nicoluzzi J, Macri M, Fukushima J, Pereira A. Celsior versus Wisconsin solution in pancreas transplantation. Transplantation Proceedings. 2008;40:3305-3307. DOI: 10.1016/j. transproceed.2008.05.080

[66] Hawthorne WJ. Beta cell therapies for type 1 diabetes. In: Hardikar AA, editor. Pancreatic Islet Biology. Switzerland: Springer Press; 2016

[67] Churchill TA. Organ Preservation for Transplantation. Functional Metabolism. John Wiley \& Sons, Inc.; 2005. pp. 529-555. DOI: 10.1002/047167558X.ch19

[68] Guibert EE, Petrenko AY, Balaban CL, Somov AY, Rodriguez JV, Fuller BJ. Organ preservation: Current concepts and new strategies for the next decade. Transfusion Medicine and Hemotherapy. 2011;38:125-142. DOI: 10.1159/000327033

[69] Chouchani ET, Pell VR, Gaude E, Aksentijevic D, SundierSY, Robb EL, etal. Ischaemicaccumulation of succinate controls reperfusion injury through mitochondrial ROS. Nature. 2014;515:431-435. DOI: 10.1038/nature13909

[70] Bon D, Chatauret N, Giraud S, Thuillier R, Favreau F, Hauet T. New strategies to optimize kidney recovery and preservation in transplantation. Nature Reviews. Nephrology. 2012;8:339-347. DOI: 10.1038/nrneph.2012.83

[71] Wahlberg JA, Love R, Landegaard L, Southard JH, Belzer FO. 72-hour preservation of the canine pancreas. Transplantation. 1987;43:5-8

[72] Chedid MF, Grezzana-Filho TJ, Montenegro RM, Leipnitz I, Hadi RA, Chedid AD, et al. First report of human pancreas transplantation using IGL-1 preservation solution: A case series. Transplantation. 2016;100:e46-e47. DOI: 10.1097/tp.0000000000001242

[73] Chen F, Nakamura T, Wada H. Development of new organ preservation solutions in Kyoto University. Yonsei Medical Journal. 2004;45:1107-1114. DOI: 10.3349/ymj.2004.45.6.1107 
[74] EurotransplantFoundation. EurotransplantManual.Leiden:Netherlands: Eurotransplant; 2016

[75] Zalewska K, Ploeg R. National Standards for Organ Retrieval from Deceased Donors (NORS Retrieval Standards). UK: Bristol; 2014

[76] Manrique A, Jimenez C, Herrero ML, Meneu JC, Abradelo M, Moreno A, et al. Pancreas preservation with the University of Wisconsin versus Celsior solutions. Transplantation Proceedings. 2006;38:2582-2584. DOI: 10.1016/j.transproceed.2006.08.058

[77] van der Plaats A, t Hart NA, Morariu AM, Verkerke GJ, Leuvenink HG, Ploeg RJ, et al. Effect of University of Wisconsin organ-preservation solution on haemorheology. Transplant International. 2004;17:227-233. DOI: 10.1007/s00147-004-0705-8

[78] Gonzalez AM, Filho GJ, Pestana JO, Linhares MM, Silva MH, Moura RM, et al. Effects of Eurocollins solution as aortic flush for the procurement of human pancreas. Transplantation. 2005;80:1269-1274

[79] Blech M, Hummel G, Kallerhoff M, Ringert RH. Electrolyte equilibration of human kidneys during perfusion with HTK-solution according to Bretschneider. Urological Research. 1997;25:331-335

[80] Troisi R, Meester D, Regaert B, Jacobs B, Van den Broucke C, Cuvelier C, et al. Physiologic and metabolic results of pancreatic cold storage with Histidine-tryptophanKetoglutarate-HTK solution (Custodiol) in the porcine autotransplantation model. Transplant International. 2000;13:98-105

[81] Hameed AM, Wong G, Laurence JM, Lam VWT, Pleass HC, Hawthorne WJ. A systematic review and meta-analysis of cold in situ perfusion and preservation for pancreas transplantation. HPB: The Official Journal of the International Hepato Pancreato Biliary Association. 2017;19:933-943. DOI: 10.1016/j.hpb.2017.07.012

[82] Fridell JA, Mangus RS, Thomas CM, Kubal CA, Powelson JA. Donation after circulatory arrest in pancreas transplantation: A report of 10 cases. Transplantation Proceedings. 2017;49:2310-2314. DOI: https://doi.org/10.1016/j.transproceed.2017.10.009

[83] Rathnasamy Muthusamy AS, Friend PJ, Dor FJM, Crane JS, Papalois V, Herbert P, et al. DCD pancreas transplantation meta-analysis: Ethical and technical considerations. Transplantation. 2017;101:e57. DOI: 10.1097/tp.0000000000001560

[84] Shahrestani S, Robertson P, Pleass HCC, Hawthorne WJ. The authors' reply. Transplantation. 2017;101:e58. DOI: 10.1097/tp.0000000000001561

[85] Berney T, Boffa C, Augustine T, Badet L, de Koning E, Pratschke J, et al. Utilization of organs from donors after circulatory death for vascularized pancreas and islet of Langerhans transplantation: Recommendations from an expert group. Transplant International. 2016;29:798-806. DOI: 10.1111/tri.12681

[86] Kuroda YKT, Suzuki Y, Fujiwara H, Yamamoto K, Saitoh Y. A new, simple method for cold storage of the pancreas using perfluorochemical. Transplantation. 1988;46:457-460 
[87] Fujino Y. Two-layer cold storage method for pancreas and islet cell transplantation. World Journal of Gastroenterology. 2010;16:3235-3238. DOI: 10.3748/wjg.v16.i26.3235

[88] Hosgood SA, Nicholson ML. The role of perfluorocarbon in organ preservation. Transplantation. 2010;89:1169-1175. DOI: 10.1097/TP.0b013e3181da6064

[89] Iwanaga Y, Sutherland DE, Harmon JV, Papas KK. Pancreas preservation for pancreas and islet transplantation. Current Opinion in Organ Transplantation. 2008;13:135-141. DOI: 10.1097/MOT.0b013e3282f63942

[90] Gruessner AC, Sutherland DE, Gruessner RW. Long-term outcome after pancreas transplantation. Current Opinion in Organ Transplantation. 2012;17:100-105. DOI: 10.1097/ MOT.0b013e32834ee700

[91] Dean PG, Kukla A, Stegall MD, Kudva YC. Pancreas transplantation. BMJ. 2017;357. DOI: $10.1136 / \mathrm{bmj} . j 1321$

[92] Dean PG, Kudva YC, StegallMD. Long-term benefits of pancreas transplantation. Current Opinion in Organ Transplantation. 2008;13:85-90. DOI: 10.1097/MOT.0b013e3282f2fd7f

[93] Gruessner RWG, Gruessner AC. The current state of pancreas transplantation. Nature Reviews. Endocrinology. 2013;9:555-562. DOI: 10.1038/nrendo.2013.138

[94] Gruessner AC, Gruessner RW. Long-term outcome after pancreas transplantation: A registry analysis. Current Opinion in Organ Transplantation. 2016;21:377-385. DOI: 10.1097/mot.0000000000000331

[95] NHS Blood and Transplant. Annual Report on Pancreas and Islet Transplantation. UK: NHS; 2017

[96] ANZIPTR. ANZIPTR Report 2017 - Australia and New Zealand Islet and Pancreas Transplant Registry Data 1984-2016. Westmead: ANZIPTR; 2017

[97] Shapiro AM, Ricordi C, Hering BJ, Auchincloss H, Lindblad R, Robertson RP, et al. International trial of the Edmonton protocol for islet transplantation. The New England Journal of Medicine. 2006;355:1318-1330. DOI: 10.1056/NEJMoa061267

[98] Barton FB. CITR Update. Melbourne: IPITA/IXA/CTS Joint Congress; 2015

[99] Hering BJ, Clarke WR, Bridges ND, Eggerman TL, Alejandro R, Bellin MD, et al. Phase 3 trial of transplantation of human islets in type 1 diabetes complicated by severe Hypoglycemia. Diabetes Care. 2016;39:1230-1240. DOI: 10.2337/dc15-1988

[100] Nadalin S, Girotti P, Konigsrainer A. Risk factors for and management of graft pancreatitis. Current Opinion in Organ Transplantation. 2013;18:89-96. DOI: 10.1097/ MOT.0b013e32835c6f0f

[101] Troppmann C, Gruessner AC, Benedetti E, Papalois BE, Dunn DL, Najarian JS, et al. Vascular graft thrombosis after pancreatic transplantation: Univariate and multivariate operative and nonoperative risk factor analysis. Journal of the American College of Surgeons. 1996;182:285-316 
[102] Farney AC, Rogers J, Stratta RJ. Pancreas graft thrombosis: Causes, prevention, diagnosis, and intervention. Current Opinion in Organ Transplantation. 2012;17:87-92. DOI: 10.1097/MOT.0b013e32834ee717

[103] Patel SR, Hakim N. Prevention and management of graft thrombosis in pancreatic transplant. Experimental and Clinical Transplantation. 2012;10:282-289

[104] Troppmann C. Complications after pancreas transplantation. Current Opinion in Organ Transplantation. 2010;15:112-118. DOI: 10.1097/MOT.0b013e3283355349

[105] Squifflet JP, LeDinh H, de Roover A, Meurisse M. Pancreas preservation for pancreas and islet transplantation: A minireview. Transplantation Proceedings. 2011;43:33983401. DOI: 10.1016/j.transproceed.2011.09.052

[106] Alonso D, Dunn TB, Rigley T, Skorupa JY, Schriner ME, Wrenshall LE, et al. Increased pancreatitis in allografts flushed with histidine-tryptophan-ketoglutarate solution: A cautionary tale. American Journal of Transplantation. 2008;8:1942-1945. DOI: 10.1111/j.1600-6143.2008.02312.x

[107] Englesbe MJ, Moyer A, Kim DY, Granger DK, Pietroski R, Yoshida A, et al. Early pancreas transplant outcomes with histidine-tryptophan-ketoglutarate preservation: A multicenter study. Transplantation. 2006;82:136-139. DOI: 10.1097/01.tp.0000225764.21343.e3

[108] Stewart ZA, Cameron AM, Singer AL, Dagher NN, Montgomery RA, Segev DL. Histidine-tryptophan-ketoglutarate (HTK) is associated with reduced graft survival in pancreas transplantation. American Journal of Transplantation. 2009;9:217-221. DOI: $10.1111 / j .1600-6143.2008 .02449 . x$

[109] Stewart ZA, Cameron AM, Singer AL, Montgomery RA, Segev DL. Histidinetryptophan-Ketoglutarate (HTK) is associated with reduced graft survival in deceased donor livers, especially those donated after cardiac death. American Journal of Transplantation. 2009;9:286-293. DOI: 10.1111/j.1600-6143.2008.02478.x

[110] Mangus RS, Fridell JA, Vianna RM, Milgrom MA, Chestovich P, Chihara RK, et al. Comparison of histidine-tryptophan-ketoglutarate solution and University of Wisconsin solution in extended criteria liver donors. Liver Transplantation. 2008;14:365-373. DOI: 10.1002/lt.21372

[111] Axelrod DA, Sung RS, Meyer KH, Wolfe RA, Kaufman DB. Systematic evaluation of pancreas allograft quality, outcomes and geographic variation in utilization. American Journal of Transplantation. 2010;10:837-845. DOI: 10.1111/j.1600-6143.2009.02996.x

[112] Blok JJ, Kopp WH, Verhagen MJ, Schaapherder AF, de Fijter JW, Putter H, et al. The value of PDRI and P-PASS as predictors of outcome after pancreas transplantation in a large European pancreas transplantation center. Pancreas. 2016;45:331-336. DOI: 10.1097/mpa.0000000000000485

[113] Suh N, Ryan B, Allen R, O'Connell P, Pleass H. Simultaneous pancreas and kidney transplantation from organ donation after cardiac death. ANZ Journal of Surgery. 2009;79:245-246. DOI: 10.1111/j.1445-2197.2009.04853.x 
[114] van Loo ES, Krikke C, Hofker HS, Berger SP, Leuvenink HGD, Pol RA. Outcome of pancreas transplantation from donation after circulatory death compared to donation after brain death. Pancreatology. 2017;17:13-18. DOI: https://doi.org/10.1016/j.pan.2016.11.002

[115] Muthusamy AS, Mumford L, Hudson A, Fuggle SV, Friend PJ. Pancreas transplantation from donors after circulatory death from the United Kingdom. American Journal of Transplantation. 2012;12:2150-2156. DOI: 10.1111/j.1600-6143.2012.04075.x

[116] Saito T, Gotoh M, Satomi S, Uemoto S, Kenmochi T, Itoh T, et al. Islet transplantation using donors after cardiac death: Report of the Japan islet transplantation registry. Transplantation. 2010;90:740-747. DOI: 10.1097/TP.0b013e3181ecb044

[117] Andres A, Kin T, O'Gorman D, Livingstone S, Bigam D, Kneteman N, et al. Clinical islet isolation and transplantation outcomes with deceased cardiac death donors are similar to neurological determination of death donors. Transplant International. 2016;29:34-40. DOI: $10.1111 /$ tri.12650

[118] Kuan KG, Wee MN, Chung WY, Kumar R, Mees ST, Dennison A, et al. Extracorporeal machine perfusion of the pancreas: Technical aspects and its clinical implications - A systematic review of experimental models. Transplantation Reviews. 2016;30:31-47. DOI: https://doi.org/10.1016/j.trre.2015.06.002

[119] Taylor MJ, Baicu SC. Current state of hypothermic machine perfusion preservation of organs: The clinical perspective. Cryobiology. 2010;60:S20-S35. DOI: 10.1016/j. cryobiol.2009.10.006

[120] Balfoussia D, Yerrakalva D, Hamaoui K, Papalois V. Advances in machine perfusion graft viability assessment in kidney, liver, pancreas, lung, and heart transplant. Experimental and Clinical Transplantation. 2012;10:87-100

[121] Hamaoui K, Gowers S, Sandhu B, Vallant N, Cook T, Boutelle M, et al. Development of pancreatic machine perfusion: Translational steps from porcine to human models. In: J Surg Res. 2018. DOI: 10.1016/j.jss.2017.11.052

[122] Barlow AD, Hamed MO, Mallon DH, Brais RJ, Gribble FM, Scott MA, et al. Use of ex vivo Normothermic perfusion for quality assessment of discarded human donor pancreases. American Journal of Transplantation. 2015;15:2475-2482. DOI: 10.1111/ ajt.13303

[123] Barlow AD, Hosgood SA, Nicholson ML. Current state of pancreas preservation and implications for DCD pancreas transplantation. Transplantation. 2013;95:1419-1424. DOI: 10.1097/TP.0b013e318285558f

[124] Taylor MJ, Baicu S, Leman B, Greene E, Vazquez A, Brassil J. Twenty-four hour hypothermic machine perfusion preservation of porcine pancreas facilitates processing for islet isolation. Transplantation Proceedings. 2008;40:480-482. DOI: 10.1016/j. transproceed.2008.01.004

[125] Leeser DB, Bingaman AW, Poliakova L, Shi Q, Gage F, Bartlett ST, et al. Pulsatile pump perfusion of pancreata before human islet cell isolation. Transplantation Proceedings. 2004;36:1050-1051. DOI: 10.1016/j.transproceed.2004.04.041 
[126] Leekmuil M, Engelse M, Ploeg RJ, de Koning E, Krikke C, Leuvenink HG, editors. Hypothermic Machine Perfusion Improves the Quality of Marginal Donor Pancreata [Abstract]. American Transplant Congress; 2015 Am J Transplant

[127] Cantarovich D, Renaudin K, Branchereau J, editors. Preservationof Human Pancreas with Hypothermic Machine Perfusion [Abstract]. Congress of the Transplantation Society. Hong Kong: Transplantation; 2016

[128] Hamaoui K, Gowers S, Sandhu B, Vallant N, Cook T, Boutelle M, et al. Development of pancreatic machine perfusion: Translational steps from porcine to human models. The Journal of Surgical Research. 2018. DOI: 10.1016/j.jss.2017.11.052

[129] Nassar A, Liu Q, Urcuyo D, Medearis S, El-Gazzaz G, Eghtesad B, et al. Establishing an ex-vivo pancreas perfusion model on discarded human grafts [abstract]. World transplant congress; 2014. Transplantation. 2014;98:376

[130] ScottWE, Weegman BP, Ferrer-Fabrega J, Stein SA, Anazawa T, Kirchner VA, et al. Pancreas oxygen Persufflation increases ATP levels as shown by nuclear magnetic resonance. Transplantation Proceedings. 2010;42:2011-2015. DOI: 10.1016/j.transproceed.2010.05.091

[131] Scott WE, O'Brien TD, Ferrer-Fabrega J, Avgoustiniatos ES, Weegman BP, Anazawa T, et al. Persufflation improves pancreas preservation when compared with the two-layer method. Transplantation Proceedings. 2010;42:2016-2019. DOI: 10.1016/j.transproceed.2010.05.092

[132] Scott WE, Rizzari MD, Stein ES, Avgoustiniatos ES, Suszynski TM, Weegman BP, et al., editors. Oxygen Persufflation of the Human Pancreas Increases ATP Levels and Improves Viable Islet Yields Compared with the two-Layer Method [Abstract]. Prague: IPITA; 2011

[133] Papas KK, Karatzas T, Purvis WG, Kitzmann JP, Gruessner A, O'Gorman D, et al., editors. Pancreas Oxygen Gas Perfusion (Persufflation) during Preservation Improves Clinical Islet Isolation Yields and Success Rates [Abstract]. Melbourne: IPITA; 2015

[134] Demiselle J, Augusto JF, Videcoq M, Legeard E, Dube L, Templier F, et al. Transplantation of kidneys from uncontrolled donation after circulatory determination of death: Comparison with brain death donors with or without extended criteria and impact of normothermic regional perfusion. Transplant International. 2016;29:432-442. DOI: 10.1111/tri.12722

[135] Butler AJ, Randle LV, Watson CJ. Normothermic regional perfusion for donation after circulatory death without prior heparinization. Transplantation. 2014;97:1272-1278. DOI: $10.1097 /$ tp.0000000000000082

[136] Oniscu GC, Randle LV, Muiesan P, Butler AJ, Currie IS, Perera MT, et al. In situ normothermic regional perfusion for controlled donation after circulatory death--the United Kingdom experience. American Journal of Transplantation. 2014;14:2846-2854. DOI: 10.1111/ajt.12927

[137] Valero R, Cabrer C, Oppenheimer F, Trias E, Sanchez-Ibanez J, De Cabo FM, et al. Normothermic recirculation reduces primary graft dysfunction of kidneys obtained from non-heart-beating donors. Transplant International. 2000;13:303-310 
[138] Lee JH, Hong SY, Oh C-K, Hong YS, Yim H. Kidney transplantation from a donor following cardiac death supported with extracorporeal membrane oxygenation. Journal of Korean Medical Science. 2012;27:115-119. DOI: 10.3346/jkms.2012.27.2.115

[139] Hessheimer AJ, Billault C, Barrou B, Fondevila C. Hypothermic or normothermic abdominal regional perfusion in high-risk donors with extended warm ischemia times: Impact on outcomes? Transplant International. 2015;28:700-707. DOI: 10.1111/tri.12344

[140] Minambres E, Suberviola B, Dominguez-Gil B, Rodrigo E, Ruiz-San Millan JC, RodriguezSan Juan JC, et al. Improving the outcomes of organs obtained from controlled donation after circulatory death donors using abdominal Normothermic regional perfusion. American Journal of Transplantation. 2017;17:2165-2172. DOI: 10.1111/ajt.14214 